\title{
TARGETED NANOMEDICINES FOR APPLICATIONS IN PRECLINICAL CANCER MODELS
}

\author{
Serena Marchio' ${ }^{1,2} \otimes$, Federico Bussolino ${ }^{1,2}$
}

'Department of Oncology; University of Turin; Candiolo, Italy

${ }^{2}$ Candiolo Cancer Institute-FPO-IRCCS; Candiolo, Italy

Despite substantial advancements in cancer management, a considerable proportion of patients cannot yet be cured. Strategies to address this open medical need are actively pursued and include two main approaches: 1) optimizing diagnostic protocols to detect tumors at early stages, and 2) designing personalized therapies to increase efficiency and selectivity of clinical interventions. Our recent work has been directed to a rationally-designed implementation of both approaches. Particularly, we have contributed to the development of nanomedicines that can be targeted to diseased tissues for theranostic purposes in preclinical models of human cancers. Such modular nanoscale systems proved to be versatile platforms to combine imaging and drug delivery for applications in the oncological field and could be a basis for future improvements.

Keywords: theranostic, cancer, targeted nanomedicines, preclinical models

$\triangle$ Correspondence should be addressed: Serena Marchio

Institute for Cancer Research and Treatment, University of Torino, 142 Km 3.95, Candiolo, Italy, 10060; serena.marchio@ircc.it

Received: 29.06.2018 Accepted: 21.08.2018

DOI: $10.24075 / \mathrm{brsmu} .2018 .081$

\section{АДРЕСНАЯ ДОСТАВКА ЛЕКАРСТВЕННЫХ НАНОПРЕПАРАТОВ В ПРИМЕНЕНИИ К МОДЕЛЯМ РАКА НА ДОКЛИНИЧЕСКОМ ЭТАПЕ ИССЛЕДОВАНИЙ}

\author{
С. Марчио ${ }^{1,2}$, Ф. Буссолино ${ }^{1,2}$ \\ Кафедра онкологии, Туринский университет, Кандиоло, Италия \\ 2 Институт онкологии (FPO-IRCCS), Кандиоло, Италия
}

\begin{abstract}
Несмотря на значительные успехи в терапии рака, большое число пациентов пока не может быть излечено. Представленные в обзоре стратегии преодоления этой проблемы активно разрабатываются по двум направлениям: 1) оптимизация диагностических протоколов для обнаружения опухолей на ранних стадиях; 2) разработка персонализированных средств терапии для увеличения эффективности и селективности лечения. Проводимые в последнее время исследования были направлены на рациональное внедрение обоих подходов, а их результаты внесли вклад в разработку нанопрепаратов, которые можно адресно доставлять к пораженным тканям в целях тераностики опухолей на доклинических моделях. Эти модульные наносистемы достаточно гибки и позволяют объединить визуализацию и таргетирование лекарств для применения в онкологии. Они могут служить базой для дальнейшего усовершенствования методов лечения рака.
\end{abstract}

Ключевые слова: наночастицы, адресная доставка лекарств, доклинические исследования, нанофармакология, онкология, тераностика

Для корреспонденции: Серена Марчио

Институт исследований и лечения рака, Университет Турина, 142 Km 3.95, Кандиоло, Италия, 10060; serena.marchio@ircc.it

Статья получена: 29.06.2018 Статья принята к печати: 21.08.2018

DOI: $10.24075 /$ vrgmu.2018.081

Early diagnosis and effective treatment of cancer are essential to minimize morbidity and mortality. These goals can be achieved by combining 1) disease-specific molecules that may serve as both diagnostic markers and therapeutic targets with 2) imaging and drug delivery tools capable of providing highperformance intervention on diseased sites without (or only marginally) affecting nearby or distant healthy tissues. Despite this broadly accepted assumption, progress in patient-tailored approaches has been relatively slow, particularly due to the paucity of suitable molecular markers. For example, of the $\sim 1,500$ proteins proposed as new cancer biomarkers in the decade 2000-2010, only < 20 have been approved by the Food and Drug Administration (FDA) to be used in routine testing [1]. On the other hand, applications of nanotechnology to medicine (collectively defined as nanomedicine) are experiencing a tremendous impact on next-generation cancer management, as demonstrated by the number of ongoing clinical trials and advanced preclinical studies [2, 3]. A nanomedicine is a therapeutic, diagnostic or combined (theranostic = therapeutic + diagnostic) agent embedded in, or otherwise associated to, a nanoparticle to provide better biodistribution, improve the efficacy and/or reduce the toxicity of the agent itself. In our studies, we identified new biomarkers and explored preclinical applications of targeted nanomedicines for cancer imaging (targeted fluorescent nanoparticles) and treatment (targeted drug-loaded liposomes). In this minireview, we outline the principal findings of these studies.

\section{Targeted molecular imaging of metastatic colorectal cancer}

Our research group has described a previously unknown complex of $\alpha_{6}$ integrin and E-cadherin, which is present on the surface of colon cancer cells but not of normal colon cells 
[4]. We have also identified a specific ligand to this receptor complex, namely angiopoietin-like 6 , a factor secreted in high amounts by normal liver and physiologically involved in lipid metabolism. We have demonstrated that this receptor/ligand circuit is operative in secondary tumor spreading: colon cancer cells expose the receptor, normal liver cells secrete the ligand, and their mutual recognition allows cancer cells to colonize the liver and eventually produce a metastatic mass in this site [4].

In addition, we have characterized two angiopoietinlike- 6 mimicking peptides that bind the $\alpha_{6}$ integrin/E-cadherin complex. These peptides, of sequence CGIYRLRS and CGVYSLRS (single letter amino acid code), besides competing with angiopoietin-like 6 for binding the receptor complex (and therefore inhibiting hepatic metastasis), represent potential tools to flag tumor cells that expose both $\alpha_{6}$ integrin and E-cadherin [4]. So, we have exploited their binding properties to design nanomedicines for cancer imaging [5]. This study was based on silica nanoparticles, which exhibit favorable toxicological profile and biocompatibility in vivo coupled to ease of manipulation in vitro $[6,7]$. We produced modular nanosystems to obtain an imaging platform consisting of fluorescent silicapolyethylene glycol (PEG) nanoparticles (SPNs) that expose either the CGIYRLRS or CGVYSLRS peptide on their surface. These SPNs have a silica nucleus associated to one or more alkoxysilane-derivatized fluorescent dyes, included in a micelle of the copolymer Pluronic ${ }^{\circledR} \mathrm{F} 127$. In other words, they consist of a PEG shell incorporating a dye-doped silica core. The external PEG provides a standard of stealth polymer for stable dispersion in physiological conditions and for prevention of uptake by the phagocyte system. Moreover, the PEG tails can be derivatized to allow covalent attachment of targeting peptides. Our SPNs have a core diameter of $11 \pm 3 \mathrm{~nm}$, a hydrodynamic diameter of $23 \mathrm{~nm}$ and are doped with either Rhodamine A (Rhod), Cyanine 5 (Cy5) (single-color), or both (dual-color). Their specificity was first investigated ex-vivo on patientderived specimens of hepatic metastasis, compared to normal liver and to primary colon cancer (Fig. 1). Sections of frozen human tissues were incubated with control (untargeted) and dual-color peptide-targeted (Rhod+Cy5)-SPNs. Nanoparticle selectivity was evaluated by confocal microscopy (imaging; Fig. 1A-D, quantification; Fig. 1E), revealing specific binding of CGIYRLRS- and CGVYSLRS-(Rhod+Cy5)-SPNs on hepatic metastasis (Fig. 1B) compared to normal liver (Fig. 1A) and colon (Fig. 1C), and to the primary tumor (Fig. 1D).

The SPNs were also tested in vivo in a mouse model of pseudo-metastatic tumor (human colon cancer cells implanted into the spleen of non-obese diabetic/severe combined immunodeficient mice, NOD/SCID; Fig. 2). Tumor-bearing mice were injected with control and targeted SPNs and signal was detected after increasing circulation times starting at 1 hour. At 6 hours, we observed a substantial reduction in background fluorescence and this signal-to-background ratio remained consistent at 16 and 24 hours. This suggests that clearance of untargeted nanoparticles is accompanied by accumulation of targeted SPNs in metastatic foci, providing a large timeframe for applications to be translated to the clinics. Fluorescence imaging by stereomicroscopy and confocal microscopy confirmed a metastasis-specific accumulation of (Rhod)CGIYRLRS-SNPS (Fig. 2A, D, G, H), (Cy5)-CGIYRLRSSNPs (Fig. 2 B, E, I, J) and (Rhod-Cy5)-CGIYRLRS-SNPs (Fig. 2C, F, K, L, M, N). A tridimensional reconstruction of several confocal microphotographs showed that the targeted SNPs localize in close proximity of tumor blood vessels (Fig. 2O, P).
The intra-operative use of fluorescence tracers is starting to emerge in prostate, gastric, urinary and ovarian cancers [8-11]. Fluorescent imaging of externally accessible human cancers, namely nonmelanoma skin tumors can be achieved [12] and endoscopic fluorescence imaging systems have also been developed for applications in colon cancer [13]. All these systems are based on untargeted fluorescent tracers, while our SPNs have the additional feature of being molecularly targeted, providing further proof of feasibility for translational consideration.

\section{Targeted drug delivery in metastatic neuroblastoma}

In the past years, we and our collaborators have also identified peptides with unique targeting features for applications in tumor treatment. Among these, CPRECES [14] and CNGRC [15] (single letter amino acid code) bind with high selectivity to the tumor endothelial/perivascular markers aminopeptidase A (APA) and N (APN), respectively, so they are optimal for in vivo applications of drug delivery via the circulation.

These two peptides were exploited in a first study aimed to define the preclinical feasibility of targeted nanomedicines for doxorubicin (DXR) delivery to models of infantile neuroblastoma [16]. For this purpose, a synthetic version of each peptide was produced as fusion with human tumor necrosis factor (TNF) and the short linker KY (single letter amino acid code), and then coupled to the PEG tails of stealth liposomes (SL) composed of distearoyl phosphatidylethanolamine (DSPE)-PEG, hydrogenated soy phosphatidylcholine (HSPC) and cholesterol. These SLs were loaded with DXR to obtain the targeted
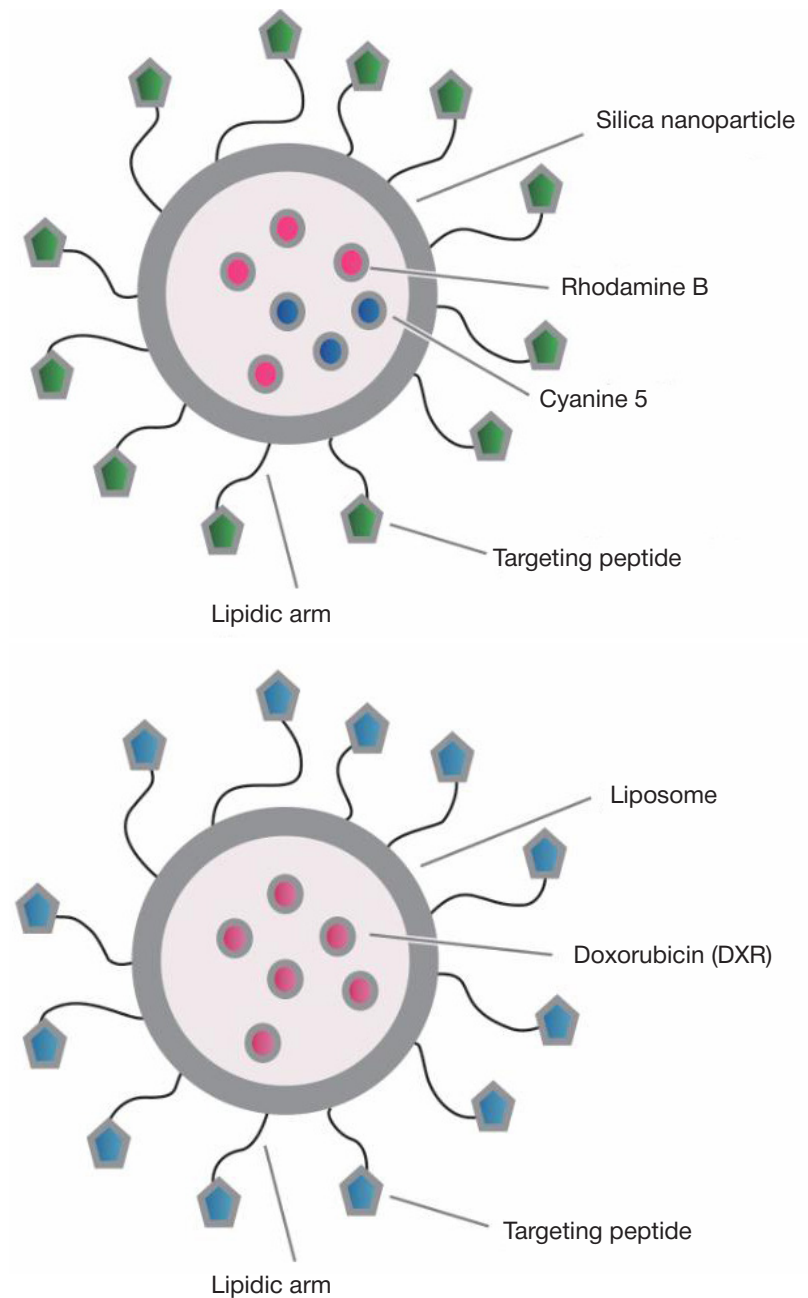
nanosystems CPRECES-SL[DXR] and CNGRC-SL[DXR], respectively, with a size of $90-115 \mathrm{~nm}$, drug entrapment of $95 \%$ and peptide coupling of $4 \mu \mathrm{g} / \mu \mathrm{mol}$ of SL. For pharmacokinetic studies, these SLs were dual-labeled by incorporation of ${ }^{3} \mathrm{H}$ and ${ }^{14} \mathrm{C}$ in cholesterol and DXR, respectively, demonstrating suitable stability and long circulation times (up to 24 hours) [16]. The efficacy of such formulations, either as a single agent or in combination regimens $(\mathrm{COMBO})$, was evaluated in orthotopic models derived by implant of human neuroblastoma cells into the left adrenal gland of nude mice. Starting 21 days after

\section{A}

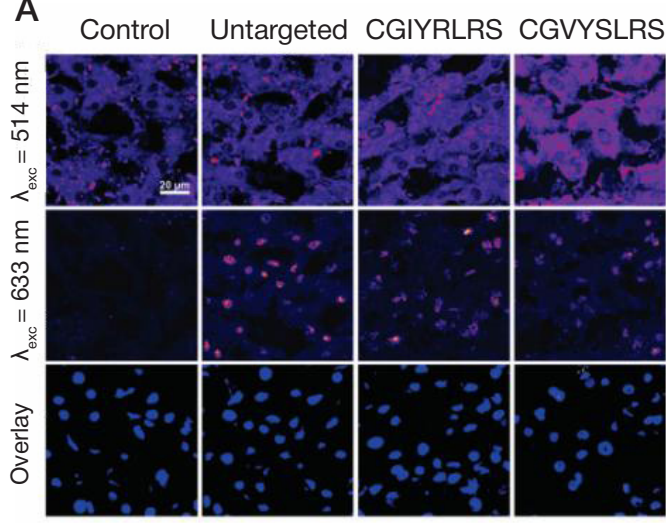

Normal liver

B Control Untargeted CGIYRLRS CGVYSLRS

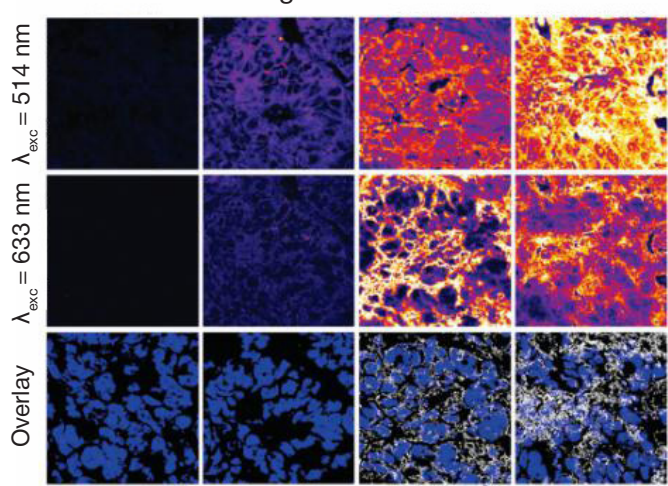

Hepatic metastasis tumor cell implant, mice were treated once a week for 5 weeks with $5 \mathrm{mg} / \mathrm{kg}$ DXR (free or liposome-incapsulated), showing that administration of CPRECES-SL[DXR], CNGRC-SL[DXR] and $\mathrm{COMBO}$ provided a consistent lifespan extension vs. the free drug (up to 17, 37 and 66 days, respectively; Fig. 3) [16].

This work demonstrates that targeting a drug to the tumor microenvironment increases its efficacy and can therefore be exploited for the development of innovative medicines.

Based on these encouraging results, in a successive study we performed combined in vitro/ex-vivo screenings of

\section{C}

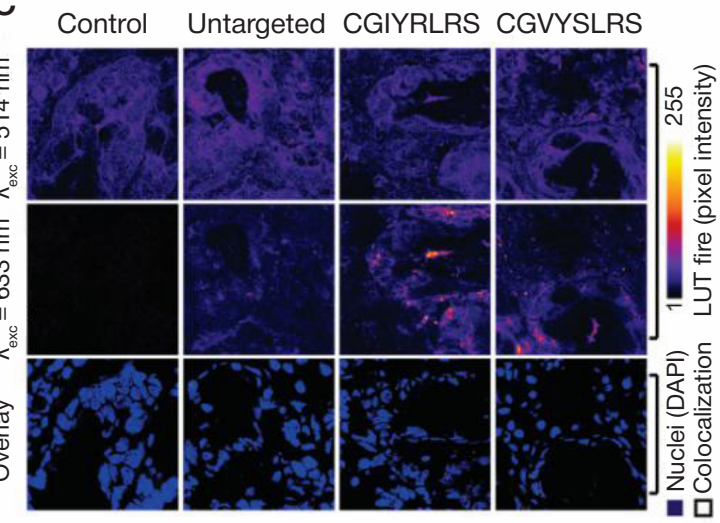

Normal colon

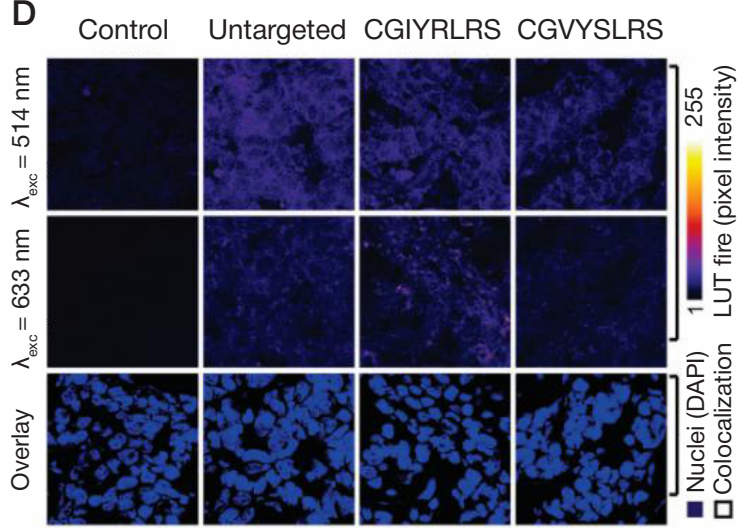

Primary tumor

E

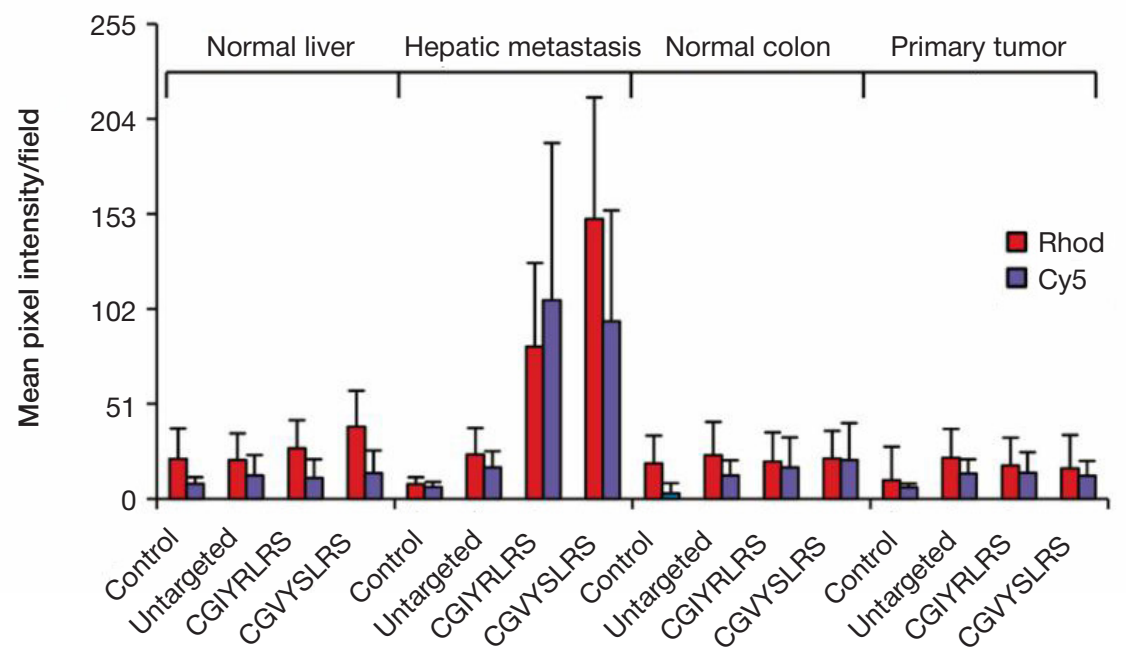

Fig. 1. Frozen sections of (A) normal liver, (B) hepatic metastasis, (C) normal colon and (D) primary tumor were fixed in $4 \%$ formaldehyde, before incubation with untargeted, CGIYRLRS-, or CGVYSLRS-(Rhod+Cy5)-SPNs for 4 hours at room temperature. After washing, SPN-emitted fluorescence was analyzed by confocal microscopy and the output was converted into the false-color LUT Fire scale for prompt visualization. Nuclei were stained with 4',6-diamidino-2-phenylindole (DAPI). Colocalized pixels were identified by ImageJ software. Experiments were performed with similar results on specimens from 10 patients with metastatic CRC; exemplary images from tissues of patient \#P85 are shown. (E) Quantification of SPN binding is expressed as the intensity of emitted pixel following excitation at 514 nm (Rhod) and $633 \mathrm{~nm}$ (Cy5), and represents a mean value of 5 images for each tissue. From Soster et al. [5] 
phage-displayed peptide libraries to identify novel peptide motifs with high specificity for human neuroblastoma [16]. These experiments were designed to isolate peptides capable of binding the whole primary tumor ( $n=26$ motifs retrieved) or metastatic mass ( $n=15$ motifs), the primary tumor microenvironment (ME) ( $n=57$ motifs) or the metastasis ME $(n=$ 23 motifs). The specificity of 5 peptides targeting the metastatic mass (phage clone \#14, peptide sequence KSFFLSH), the primary tumor ME (\#1, YEGLISR) and the metastasis ME (\#5, HSYWLRS; \#8, WSWPREL; \#10, ALAAHKL) was confirmed ex vivo by binding assays on sections of human stage IV neuroblastoma and in vivo in mouse models. These peptides were therefore synthetized with the addition of an $N$-terminal (YSHS, single letter amino acid code) and a $\mathrm{C}$-terminal (GGG, single letter amino acid code) linkers and coupled to SLs as described above [16]. The potential efficacy of these nanosystems was tested in an orthotopic model derived from implant of luciferase-transduced human neuroblastoma cells; in addition, a pseudo-metastatic model was obtained by tumor cell injection in the tail vein of nude mice. Orthotopically-implanted
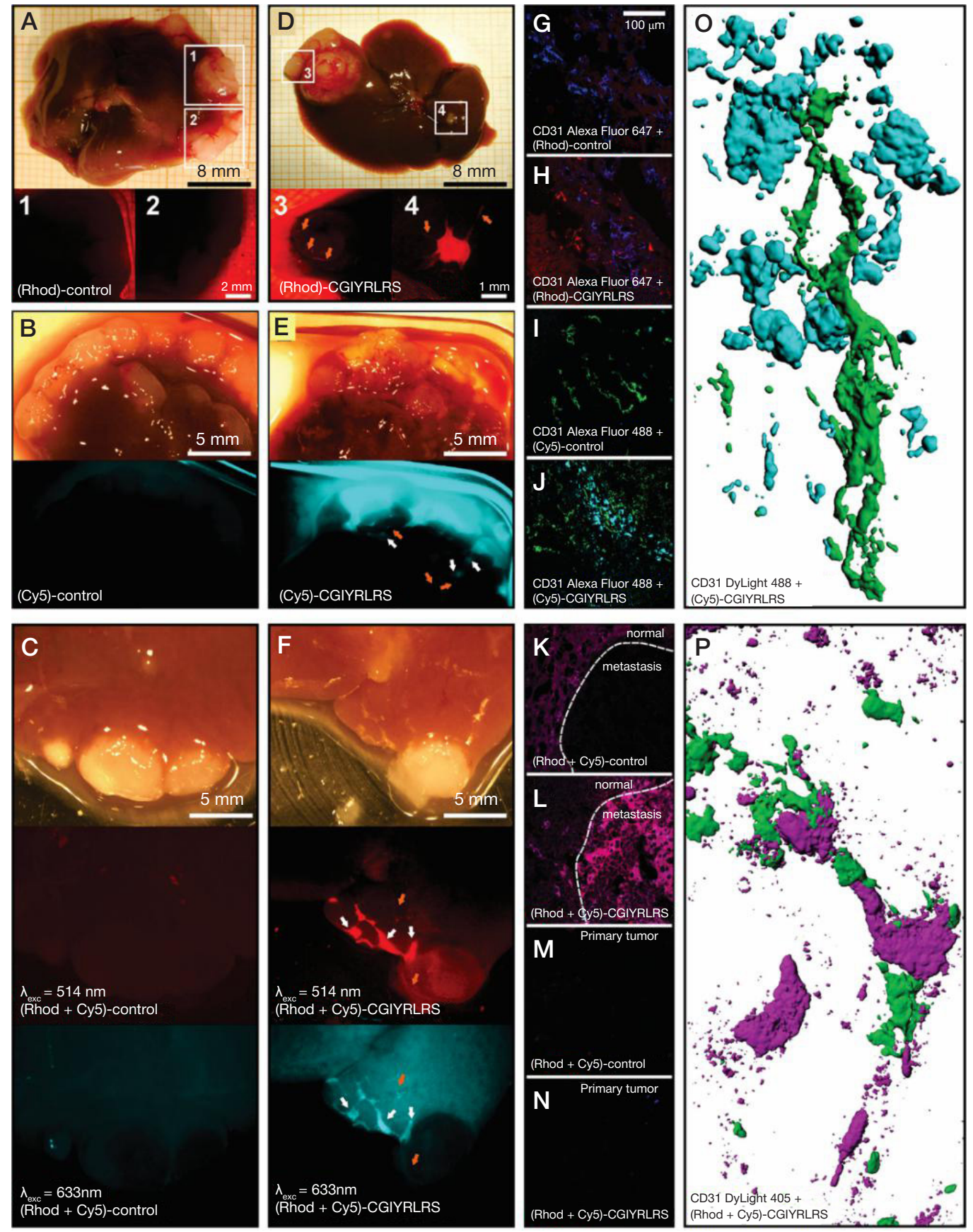

Fig. 2. NOD/SCID mice bearing a primary tumor and multiple liver metastases were injected with single- [control (A, Rhod; B, Cy5) or CGIYRLRS- (D, Rhod; E, Cy5)] or dual-color [control (C) or CGIYRLRS (F)] SPNs. After 16 hours, mice were euthanized and explanted organs were photographed with a high-resolution digital camera connected to a fluorescence stereomicroscope. In $\mathbf{D}, \mathbf{E}$, and $\mathbf{F}$, orange arrows indicate blood vessels crossing the hepatic metastasis; in $\mathbf{E}$ and $\mathbf{F}$, white arrows indicate sub-millimetric metastatic foci. Samples of the same tissues were OCT-frozen, cut into 10- $\mu \mathrm{m}$ slices, and evaluated by confocal analysis of single- [control (G, Rhod; I, Cy5), CGIYRLRS (H, Rhod; J, Cy5)] or dual-color [control (K), CGIYRLRS (L)] fluorescence. To visualize blood vessels, staining for CD31 was superimposed to the SPNs signal and visualized by the secondary antibodies Alexa Fluor ${ }^{\circledR} 647$ (G-H), Alexa Fluor ${ }^{\circledR} 488(\mathbf{I}-\mathbf{J})$ and DyLight ${ }^{\top \mathrm{TM}} 405(\mathbf{K}-\mathbf{N})$, for overlay with (Rhod)-SPNs, (Cy5)-SPNs and dual-color SPNs, respectively. In the case of dual-color SPNs, samples of primary tumors from mice injected with either control (M) or CGIYRLRS (N) SPNs are visualized as a further negative control. In $\mathbf{O}$ (detail of the field in $\mathbf{J}$ ) and $\mathbf{P}$ (detail of the field in $\mathbf{L}$ ), tridimensional models of 50-80 confocal image series were reconstructed with IMARIS software. From Soster et al. [5] 
mice were treated once a week for 3 weeks starting 21 days after tumor cell implant, and intravenously-implanted mice were treated with the same schedule but starting 4 hours after tumor cell implant. In a first series of experiments, growth of luciferase-expressing orthotopic tumors was monitored by bioluminescence imaging (BLI) at days 26, 33, 40 after implant (5 days after each treatment) showing that 5-SL[DXR] and 10-SL[DXR] were the most efficient in delaying tumor progression, as also confirmed by a whole-body X-ray scan performed one month after the end of treatments (Fig. 4A). Successively, the capacity of targeted formulations to prolong the lifespan of tumor-bearing mice was evaluated in both the pseudo-metastatic (Fig. 4B) and the orthotopic (Fig. 4C) model. Again, treatment with 5-SL[DXR] or 10-SL[DXR] provided a survival advantage to neuroblastoma-bearing mice when compared to control animals or even to animals treated with DXR, either free or included in untargeted liposomal formulations [16].

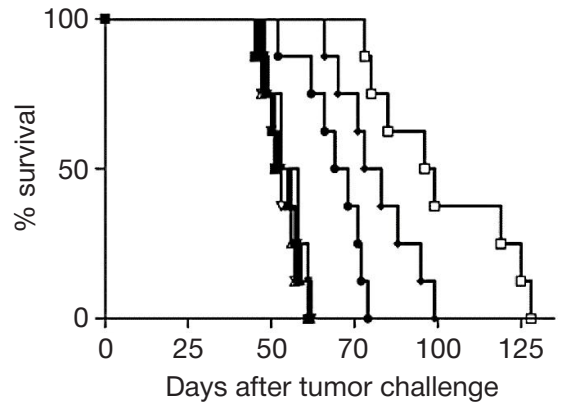

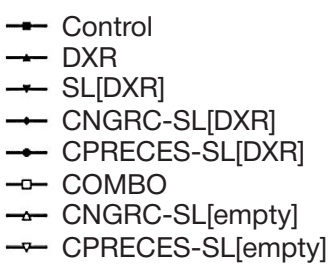

$\rightarrow$ CPRECES-SL[empty]

Fig. 3. Therapeutic efficacy of APN- and APA-targeted liposomal formulations in mouse models of neuroblastoma. Nude mice (8/group) implanted orthotopically with human neuroblastoma cells were treated (starting 21 days after tumor implant) by intravenous administration of HEPES-buffered saline (control), CNGRC-SL[empty], CPRECES-SL[empty] or $5 \mathrm{mg} / \mathrm{kg}$ of DXR, either free (DXR) or encapsulated in untargeted (SL[DXR]), APN- (CNGRC-SL[DXR]) or APA-targeted (CNGRC-SL[DXR]) liposomes or an equimolar mixture of CNGRC-SL[DXR] and CNGRC-SL[DXR] (COMBO), once-a-week for a total of 5 weeks. The efficacy of each formulation was evaluated in terms of survival and is expressed in a Kaplan-Maier graph as \% of alive mice at different timepoints. From Loi et al. [18]

\section{A}

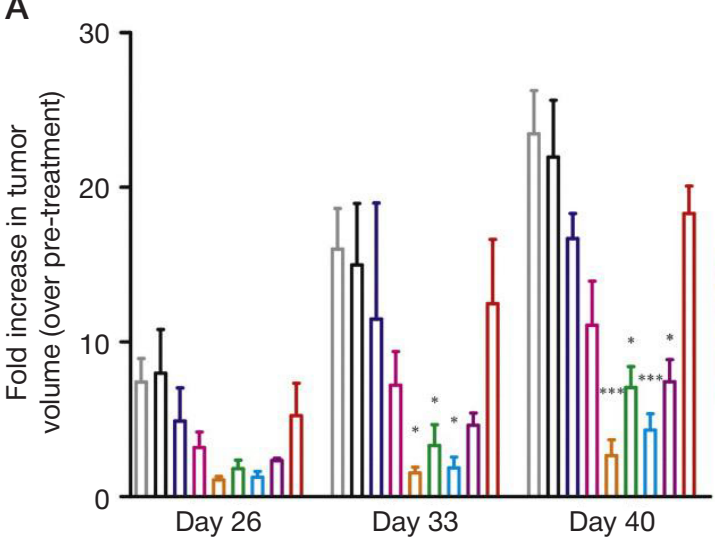

B

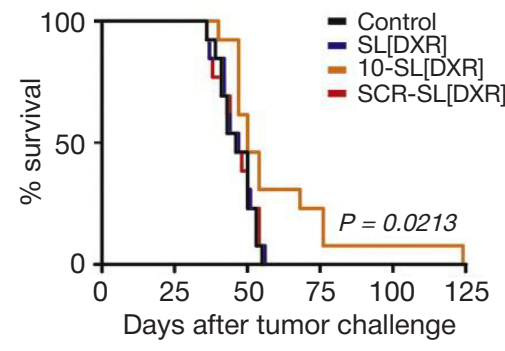

C

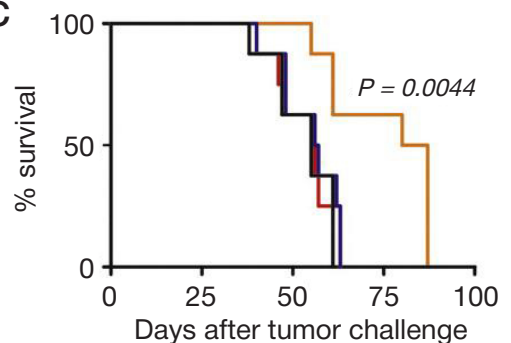

x-ray (day 65)

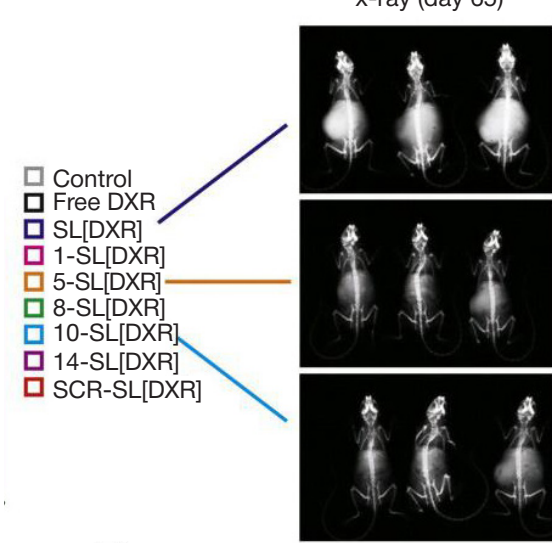

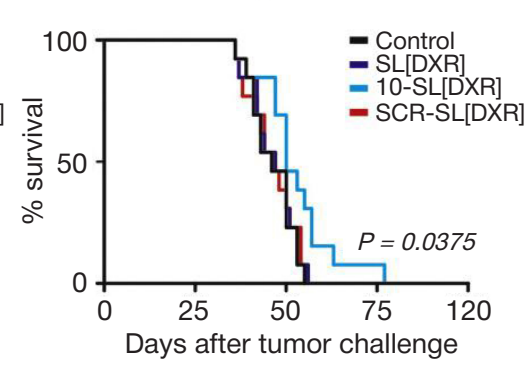

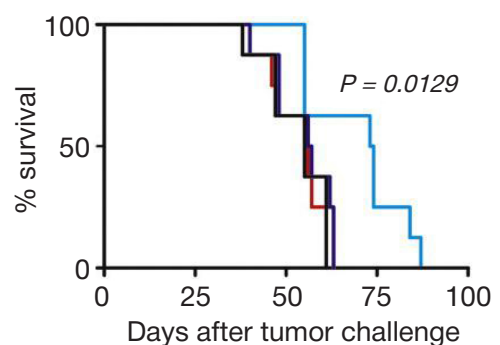

Fig. 4. (A) Therapeutic efficacy of peptide-targeted liposomal formulations in mouse models obtained by orthotopic implant of luciferase-expressing human neuroblastoma cells. Treatments started 21 days after tumor implant. Mice (5/group) were administered intravenous with HEPES-buffered saline (control), or 5 mg/kg of DXR, either free (DXR) or encapsulated in untargeted (SL[DXR]), scramble peptide- (SCR-SL[DXR] or targeting peptide-functionalized (1-, 5-, 8-, 10-, 14-SL[DRX]) liposomes, once-a-week for a total of 3 weeks. Tumor growth was monitored by BLI 5 days after each treatment (days $26,33,40$ from tumor implant). Values are reported as fold increase in tumor volume compared to pre-treatment (day 20). Exemplary pictures of X-ray acquisitions one month after the end of treatment (day 65), relative to mice treated with SL[DXR], 5-SL[DXR] or 10-SL[DXR], are shown. (B-C) Therapeutic effect of the targeted formulations evaluated in terms of overall survival in both the pseudo-metastatic model (13 animals/ group, B) and the orthotopic model (8 animals/group, C). Statistical analysis: A, $p$ vs. SL[DXR]; B-C, $p$ vs. control, SL[DXR] and SCR-SL[DXR]. From Loi et al. [16]. 
These preliminary findings were complemented by a successive in-depth characterization of the HSYWLRS peptide (\#5 of the previous study) as a targeting moiety in preclinical applications [17]. Binding and internalization specificity was confirmed on additional cell lines and tissue specimens from animal models and human stage IV neuroblastoma. DXR-loaded, peptide-targeted SLs (HSWYLRS-SL[DXR]) were therefore produced and tested as in vivo drug delivery nanosystems. Vascular permeability was evaluated by administration of Evans Blue in neuroblastoma-bearing mice treated with HSYWLRS$S L[D X R]$, observing a specific increase in dye extravasation and accumulation in orthotopic tumors, but not in non-tumor tissues (Fig. 5A). Treatment with HSYWLRS-SL[DXR] also increased perfusion of tumor blood vessels, as determined by intravenous injection of fluorescein isothiocyanate (FITC)-lectin and analysis of emitted fluorescence by confocal microscopy (Fig. 5B). These phenomena were accompanied by (1) enhanced tumor

A

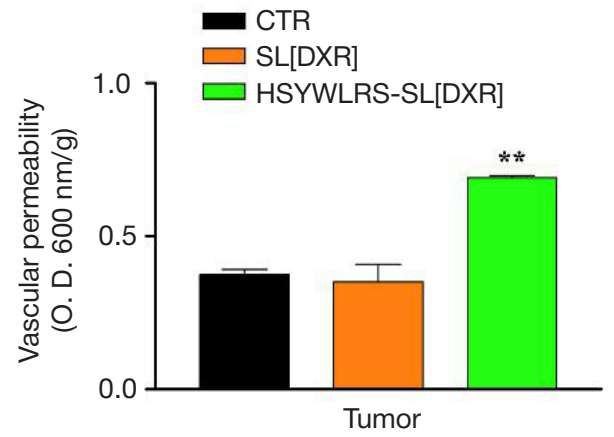

B

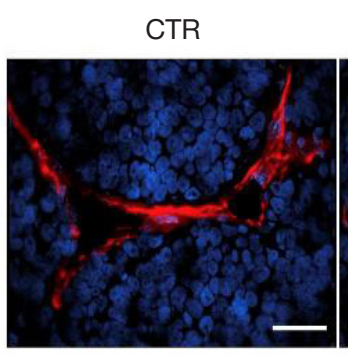
SL[DXR]

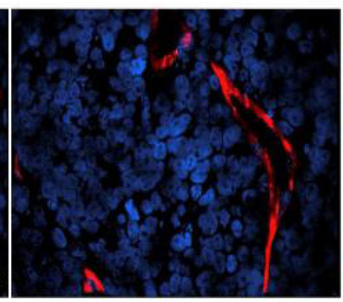

C

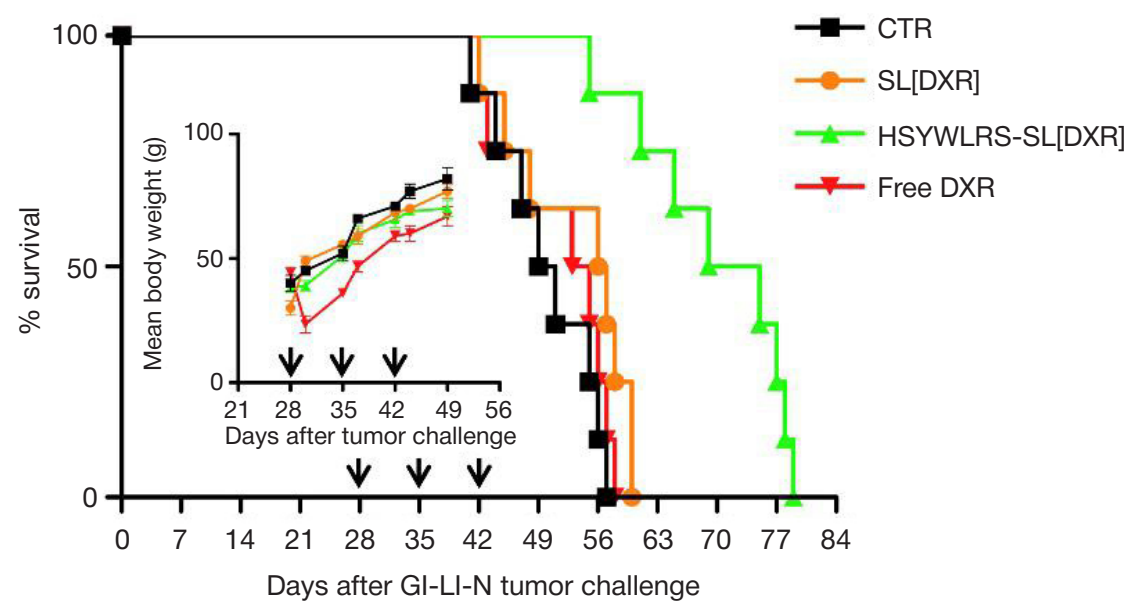

Fig. 5. (A) In vivo systemic permeability. Mice (3/group) bearing orthotopic tumors were treated, 28 days after, with a single bolus of DXR (5 mg/kg), encapsulated into untargeted (SL[DXR]) or HSYWLRS-targeted (HSYWLRS-SL[DXR]) liposomes, in combination with 1 mg of Evans Blue dye. Control mice (CTR) received HEPESbuffered saline only. One hour after, mice were perfused, tumors and livers collected and Evans Blue extracted and quantified (O.D. 600 nm). Results are expressed as Evans Blue dye per $g$ of tissue. ${ }^{* *}, p<0.01$ : HSYWLRS-SL[DXR] vs. CTR and SL[DXR]. (B) Exemplary tumor sections from control mice or from mice treated with SL[DXR] or HSYWLRS-SL[DXR] and inoculated with FITC-lectin (green). Red: CD31. Blue: cell nuclei (DAPI). Scale bar: 40 um. Graph on the right, numbers of FITClectin positive cells. ${ }^{* *}, p<0.001$, HSYWLRS-SL[DXR] vs. CTR and SL[DXR]. (C) Potentiated therapeutic efficacy of HSYWLRS-SL[DXR]. Mice (8/group) bearing orthotopic tumors were treated intravenous with $5 \mathrm{mg} / \mathrm{kg}$ of DXR, either free (free DXR) or encapsulated into SL[DXR] or HSYWLRS-SL[DXR] liposomes, once-a-week for 3 weeks (arrows). Control mice received HEPES buffer only (CTR). Survival: $p<0.0008$ : HSYWLRS-SL[DXR] vs. SL[DXR]). Insert: mean body weight at different timepoints. From Cossu et al. [17] 
A
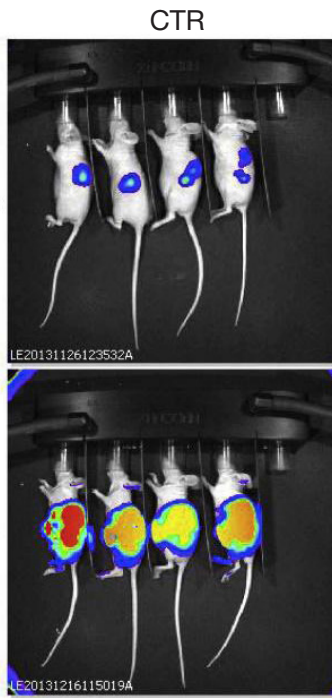

B

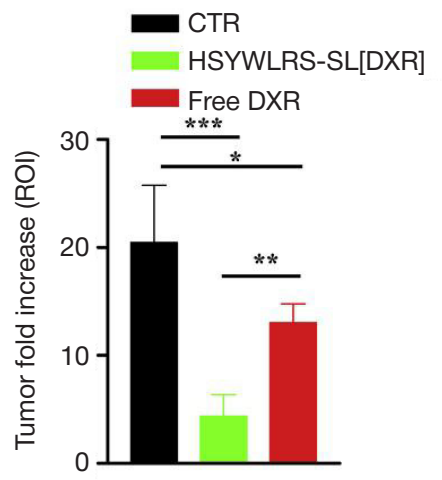

HSYWLRS-SL[DXR]
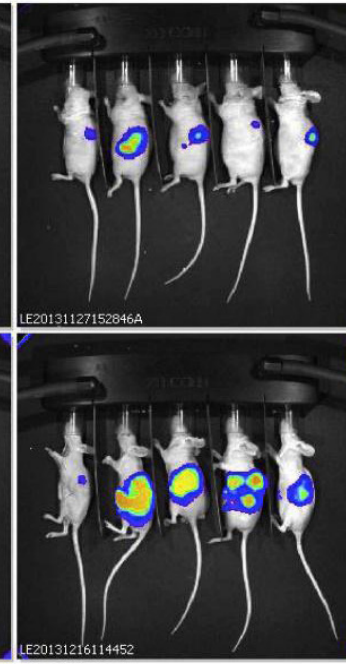

C

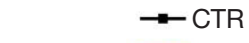

$=$ HSYWLRS-SL[DXR]

$\rightarrow$ Free DXR

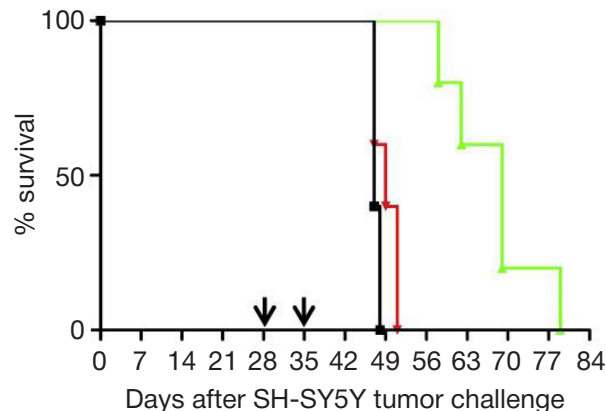

Fig. 6. (A) Lateral (tumor side) images from mice orthotopically implanted with luciferase-expressing human neuroblastoma cells. Animals were treated intravenously, once a week for 2 weeks (arrows), with $5 \mathrm{mg} / \mathrm{kg}$ of DXR, either free (free DXR) or encapsulated into HSYWLRS-targeted liposomes (HSYWLRS-SL[DXR]). CTR mice received HEPES-buffered saline. Tumor growth was monitored by BLI at day 20 (before treatment) and 40 (end of treatments) after tumor challenge. (B) Antitumor effects at the end of treatments; values are reported as fold increase in tumor volume at day 40 over day $20 .{ }^{\star}, p<0.05:$ free DXR vs. CTR; ${ }^{* *}, p<0.01$ : HSYWLRSSL[DXR] vs. free DXR; ${ }^{* \star \star}, p<0.001$ : HSYWLRS-SL[DXR] vs. CTR; (C) HSYWLRS-SL[DXR] show potentiated therapeutic efficacy. Survival: $p<0.0025$ : HSYWLRSSL[DXR] vs. CTR and free DXR. From Cossu et al. [17]

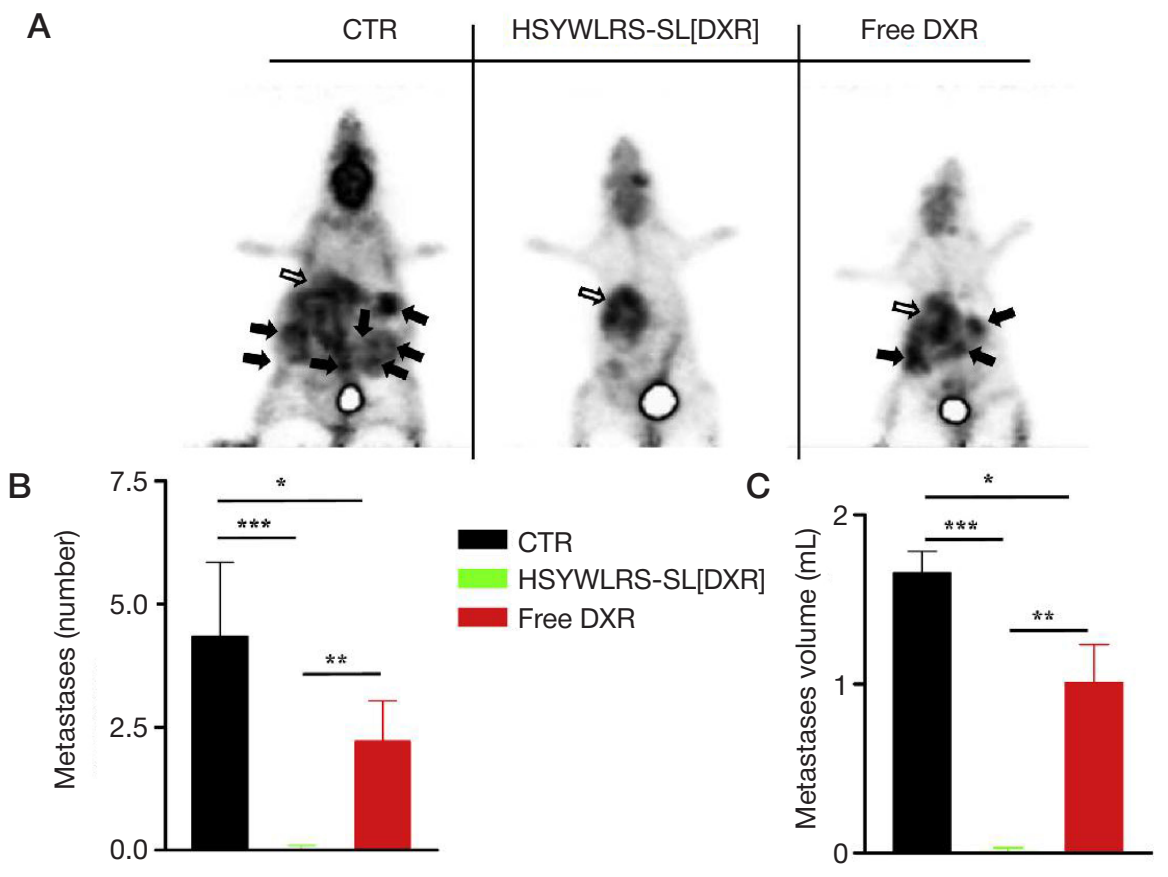

Fig. 7. Treatment with HSYWLRS-SL[DXR] inhibits secondary tumor spreading. Mice (4/CTR, 5/treatments) orthotopically implanted with luciferase-expressing human neuroblastoma cells were treated as reported in the legend of Figure 6 and tumor extension was evaluated by PET after 41 days (A). Glucose consumption maps (white arrows: primary tumor; black arrows: metastases). (B) Number and (C) volume of metastases following treatments. ${ }^{*}, p<0.05$ : free DXR vs. CTR; ${ }^{* *}$, $p<0.01$ : HSYWLRSSL[DXR] vs. free DXR; ${ }^{\star \star *}, p<0.001$ : HSYWLRS-SL [DXR] vs. CTR 
Together, these data support the development of the neuroblastoma-targeting peptide HSYWLRS as a powerful tool for therapeutic applications.

\section{CONCLUSIONS}

Early tumor diagnosis and efficient treatment (namely, a treatment that reaches max antitumor efficacy while sparing normal tissues) remain an open medical need. The advent of nanomedicine is delivering new tools that could revolutionize our approach to cancer monitoring and therapy, provided that we identify biomarkers with suitable properties. In fact, while the development of nanomaterials is rapidly expanding, we still need more selective targets to allow patienttailored approaches. In this perspective, our recent work contributed a number of targets and targeting moieties that were validated preclinically and could be exploited to develop clinical tools.

\section{References}

1. Arap W, Pasqualini R, Montalti M, Petrizza L, Prodi L, Rampazzo E et al. Luminescent silica nanoparticles for cancer diagnosis. Curr Med Chem. 2013; 20 (17): 2195-211.

2. Bobo D, Robinson KJ, Islam J, Thurecht KJ, Corrie SR Nanoparticle-based medicines: a review of FDA-approved materials and clinical trials to date. Pharm Res. 2016; 33 (10): 2373-87.

3. Caster JM, Patel AN, Zhang T, Wang A. Investigational nanomedicines in 2016: a review of nanotherapeutics currently undergoing clinical trials. Rev Nanomed Nanobiotechnol. 2017; 9 (1): e1456.

4. Marchiò S, Soster M, Cardaci S, Muratore A, Bartolini A, Barone V et al. A complex of alpha(6) integrin and E-cadherin drives liver metastasis of colorectal cancer cells through hepatic angiopoietinlike 6. EMBO Mol Med. 2012 Nov; 4 (11): 1156-75.

5. Soster $M$, Juris $R$, Bonacchi $S$, Genovese D, Montalti $M$, Rampazzo E et al. Targeted dual-color silica nanoparticles provide univocal identification of micrometastases in preclinical models of colorectal cancer. Int J Nanomed. 2012; (7): 4797-807.

6. Bonacchi S, Genovese D, Juris R, Montalti M, Prodi L, Rampazzo E et al. Luminescent chemosensors based on silica nanoparticles. Top Curr Chem. 2011; (300): 93-138.

7. Bonacchi S, Genovese D, Juris R, Montalti M, Prodi L, Rampazzo E et al. Luminescent silica nanoparticles: extending the frontiers of brightness. Angew Chem Int Ed Engl. 2011; 50 (18): 4056-66.

8. D'Hallewin MA, Kamuhabwa AR, Roskams T, De Witte PA, Baert L. Hypericin-based fluorescence diagnosis of bladder carcinoma. BJU Int. 2002; 89 (7): 760-3.

9. Miyashiro I, Miyoshi N, Hiratsuka M, Kishi K, Yamada T, Ohue M et al. Detection of sentinel node in gastric cancer surgery by indocyanine green fluorescence imaging: comparison with infrared imaging. Ann Surg Oncol. 2008; 15 (6): 1640-3.

10. van Dam GM, Themelis G, Crane LM, Harlaar NJ, Pleijhuis RG, Kelder $\mathrm{W}$ et al. Intraoperative tumor-specific fluorescence imaging

\section{Литература}

1. Arap W, Pasqualini R, Montalti M, Petrizza L, Prodi L, Rampazzo E et al. Luminescent silica nanoparticles for cancer diagnosis. Curr Med Chem. 2013; 20 (17): 2195-211.

2. Bobo D, Robinson KJ, Islam J, Thurecht KJ, Corrie SR. Nanoparticle-based medicines: a review of FDA-approved materials and clinical trials to date. Pharm Res. 2016; 33 (10): 2373-87.

3. Caster JM, Patel AN, Zhang T, Wang A. Investigational nanomedicines in 2016: a review of nanotherapeutics currently undergoing clinical trials. Rev Nanomed Nanobiotechnol. 2017; 9 (1): e1456.

4. Marchiò S, Soster M, Cardaci S, Muratore A, Bartolini A, Barone V et al. A complex of alpha(6) integrin and E-cadherin drives liver metastasis of colorectal cancer cells through hepatic angiopoietinlike 6. EMBO Mol Med. 2012 Nov; 4 (11): 1156-75.

5. Soster $\mathrm{M}$, Juris $\mathrm{R}$, Bonacchi $\mathrm{S}$, Genovese $\mathrm{D}$, Montalti $\mathrm{M}$, Rampazzo E et al. Targeted dual-color silica nanoparticles provide

in ovarian cancer by folate receptor-alpha targeting: first in-human results. Nat Med. 2011; 17 (10): 1315-9.

11. van der Poel HG, Buckle T, Brouwer OR, Valdes Olmos RA, van Leeuwen FW. Intraoperative laparoscopic fluorescence guidance to the sentinel lymph node in prostate cancer patients: clinical proof of concept of an integrated functional imaging approach using a multimodal tracer. Eur Urol. 2011; 60 (4): 826-33.

12. de Leeuw J, van der Beek N, Neugebauer WD, Bjerring P, Neumann HA. Fluorescence detection and diagnosis of nonmelanoma skin cancer at an early stage. Lasers Surg Med. 2009; 41 (2): 96-103.

13. Atlamazoglou V, Yova D, Kavantzas N, Loukas S. Microscopical examination of the localisation patterns of two novel rhodamine derivatives in normal and neoplastic colonic mucosa. Lasers Med Sci. 2001; 16 (4): 253-9.

14. Marchiò S, Lahdenranta J, Schlingemann RO, Valdembri D, Wesseling P, Arap MA et al. Aminopeptidase A is a functional target in angiogenic blood vessels. Cancer Cell. 2004; 5 (2): 151-62.

15. Pasqualini R, Koivunen E, Kain R, Lahdenranta J, Sakamoto M, Stryhn A. Aminopeptidase $\mathrm{N}$ is a receptor for tumor-homing peptides and a target for inhibiting angiogenesis. Cancer Res. 2000; 60 (3): 722-7.

16. Loi M, Di Paolo D, Soster M, Brignole C, Bartolini A, Emionite L et al. Novel phage display-derived neuroblastoma-targeting peptides potentiate the effect of drug nanocarriers in preclinical settings. J Control Release. 2013; 170 (2): 233-41.

17. Cossu I, Bottoni G, Loi M, Emionite L, Bartolini A, Di Paolo D et al. Neuroblastoma-targeted nanocarriers improve drug delivery and penetration, delay tumor growth and abrogate metastatic diffusion. Biomaterials. 2015; (68): 89-99.

18. Loi M, Marchiò S, Becherini P, Di Paolo D, Soster M, Curnis F et al. Combined targeting of perivascular and endothelial tumor cells enhances anti-tumor efficacy of liposomal chemotherapy in neuroblastoma. J Control Release. 2010; 145 (1): 66-73. univocal identification of micrometastases in preclinical models of colorectal cancer. Int J Nanomed. 2012; (7): 4797-807.

6. Bonacchi S, Genovese D, Juris R, Montalti M, Prodi L, Rampazzo E et al. Luminescent chemosensors based on silica nanoparticles. Top Curr Chem. 2011; (300): 93-138.

7. Bonacchi S, Genovese D, Juris R, Montalti M, Prodi L, Rampazzo E et al. Luminescent silica nanoparticles: extending the frontiers of brightness. Angew Chem Int Ed Engl. 2011; 50 (18): 4056-66.

8. D'Hallewin MA, Kamuhabwa AR, Roskams T, De Witte PA, Baert L. Hypericin-based fluorescence diagnosis of bladder carcinoma. BJU Int. 2002; 89 (7): 760-3.

9. Miyashiro I, Miyoshi N, Hiratsuka M, Kishi K, Yamada T, Ohue M et al. Detection of sentinel node in gastric cancer surgery by indocyanine green fluorescence imaging: comparison with infrared imaging. Ann Surg Oncol. 2008; 15 (6): 1640-3.

10. van Dam GM, Themelis G, Crane LM, Harlaar NJ, Pleijhuis RG, Kelder $W$ et al. Intraoperative tumor-specific fluorescence imaging 


\section{REVIEW I NANOMEDICINE}

in ovarian cancer by folate receptor-alpha targeting: first in-human results. Nat Med. 2011; 17 (10): 1315-9.

11. van der Poel HG, Buckle T, Brouwer OR, Valdes Olmos RA, van Leeuwen FW. Intraoperative laparoscopic fluorescence guidance to the sentinel lymph node in prostate cancer patients: clinical proof of concept of an integrated functional imaging approach using a multimodal tracer. Eur Urol. 2011; 60 (4): 826-33.

12. de Leeuw J, van der Beek N, Neugebauer WD, Bjerring P, Neumann HA. Fluorescence detection and diagnosis of nonmelanoma skin cancer at an early stage. Lasers Surg Med. 2009; 41 (2): 96-103.

13. Atlamazoglou V, Yova D, Kavantzas N, Loukas S. Microscopical examination of the localisation patterns of two novel rhodamine derivatives in normal and neoplastic colonic mucosa. Lasers Med Sci. 2001; 16 (4): 253-9.

14. Marchiò S, Lahdenranta J, Schlingemann RO, Valdembri D, Wesseling P, Arap MA et al. Aminopeptidase A is a functional target in angiogenic blood vessels. Cancer Cell. 2004; 5 (2): 151-62.

15. Pasqualini R, Koivunen E, Kain R, Lahdenranta J, Sakamoto M, Stryhn A. Aminopeptidase $\mathrm{N}$ is a receptor for tumor-homing peptides and a target for inhibiting angiogenesis. Cancer Res. 2000; 60 (3): 722-7.

16. Loi M, Di Paolo D, Soster M, Brignole C, Bartolini A, Emionite L et al. Novel phage display-derived neuroblastoma-targeting peptides potentiate the effect of drug nanocarriers in preclinical settings. J Control Release. 2013; 170 (2): 233-41.

17. Cossu I, Bottoni G, Loi M, Emionite L, Bartolini A, Di Paolo D et al. Neuroblastoma-targeted nanocarriers improve drug delivery and penetration, delay tumor growth and abrogate metastatic diffusion. Biomaterials. 2015; (68): 89-99.

18. Loi M, Marchiò S, Becherini P, Di Paolo D, Soster M, Curnis F et al. Combined targeting of perivascular and endothelial tumor cells enhances anti-tumor efficacy of liposomal chemotherapy in neuroblastoma. J Control Release. 2010; 145 (1): 66-73. 